Д-р техн. наук О.Б. Бабанін, асист. О.С. Коваленко

\title{
ОРГАНІЗАЦІ ПРОВЕДЕННЯ ВИПРОБУВАНЬ СИЛОВОГО ОБЛАДНАННЯ ТЯГОВОГО РУХОМОГО СКЛАДУ 3 УРАХУВАННЯМ ЕФЕКТИВНОГО РИЗИКУ
}

\begin{abstract}
Постановка проблеми. Про надійність силового обладнання тягового рухомого складу (ТРС) найбільш ефективно можна судити за результатами його роботи в експлуатації. Однак вельми актуальною залишається проблема розробки комплексу заходів 3 метою підтвердження заданого рівня надійності до установлення його на рухомий склад. Найважливіші з таких заходів - проведення групових випробувань на спеціальних стендах. Для організації та проведення таких випробувань потрібно вирішити непрості завдання. Основне 3 них - як на основі малого часу на проведення випробувань отримати достовірну оцінку безвідмовності при подальшій експлуатації.

Аналіз останніх досліджень i публікацій. Існуюча система проведення випробувань силових вузлів тягового рухомого складу має значні недоліки, які полягають у тому, що кожен вузол випробовується окремо тільки на своєму стенді, не враховуючи його зв'язки i характеристики інших силових вузлів i
\end{abstract}

систем локомотива. Ця обставина викликає витрати часу на додаткові випробування вже встановленого на локомотиві обладнання та їх доведення.

Формулювання мети статті. Метою даної статті є необхідність вишукати такі основи випробувань, які дозволили б розробити плани і програми їх проведення з урахуванням ефективного ризику.

Виклад основного матеріалу. Збиток вирішальної функції (прийняти або забракувати випробовуваний зразок) відповідно до [1,5] пов'язаний з ризиками прийняття неправильних рішень $\varepsilon(R)$ i $\phi(R)$. В даному випадку $R$ являє собою рівень безвідмовності випробовувального вузла. При цьому має місце така схема. Нехай ймовірність відмови зразка силового обладнання за період безперервної роботи $T$ дорівнюе $z$. Тоді, якщо $z<z^{*}$ (де $z^{*}-$ заданиий рівень), зразок відповідає вимогам щодо безвідмовності, при $z>z^{*}$ - він цим вимогам не відповідає. Величина зазвичай називається бракувальним рівнем 
(показником). 3 огляду на те, що при виборі $z \in R$ вирішується статистична задача, ризики $\varepsilon(R)$ і $\phi(R)$ відмінні від нуля.

3 урахуванням безвідмовності зразка ïх значення визначаються таким чином $[2,4]$ :

$$
\begin{aligned}
& \phi(R, z)=\left\{\begin{array}{l}
0, z<z * \\
P(z), z \geq z *
\end{array}\right. \\
& \varepsilon(R, z)=\left\{\begin{array}{l}
1-P(z), z>z^{*} \\
0, z \geq z *
\end{array},\right.
\end{aligned}
$$

де $P(z)$ - імовірність прийняття зразка, безвідмовність якого характеризується $z$.

Функції $\varepsilon(R, z)$ і $\phi(R, z)$ досягають максимуму в точці $z=z^{*}$, тобто

$$
\left.\begin{array}{l}
\varepsilon\left(R, z^{*}\right)=\max _{z} \varepsilon(R, z) \equiv \varepsilon ; \\
\phi\left(R, z^{*}\right)=\max _{z} \phi(R, z) \equiv \phi ;
\end{array}\right\},
$$

де $\varepsilon$ і $\phi$ відомі як ризики постачальника і замовника відповідно [3].

Функція $P(z)$ являє собою оперативну характеристику плану випробувань (рис. 1), де, взагалі кажучи, $\varepsilon=1-\phi . \quad$ Разом 3 тим прагнення отримати одночасно досить малі значення $\varepsilon$ i $\phi$ змушує вдаватися до штучного прийому - задавати область нечутливості, тобто, крім бракувального $z_{2}$, задавати деякий приймальний рівень $z_{1}$ (і відповідні значення ризику $\phi^{\prime}$ і $\varepsilon^{\prime}$ ).

У цьому випадку при $0 \leq z \leq z_{1}$ вважається, що зразок відповідає вимогам щодо безвідмовності, при $z_{2} \leq z \leq 1$ він цим вимогам не відповідає, а при $z_{1} \leq z \leq z_{2}$ має область нечутливості (для виходу за межі останньої нерівності потрібна додаткова інформація).

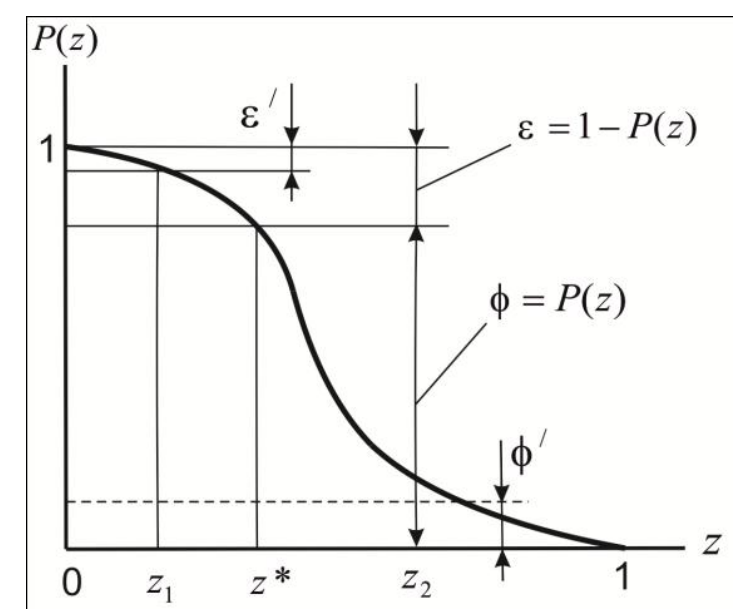

Рис. 1. Оперативна характеристика плану випробувань

Серйозний недолік такого підходу виявляється в тому, що при зниженні значень $\varepsilon$ i $\phi$ до прийнятного рівня $(\leq 0,4)$ його реалізація пов'язана 3 невиправдано великим обсягом випробувань. Причину цього слід шукати в способі призначення $\varepsilon$ i $\phi$, які являють собою умовні ймовірності: $\phi$-умовна ймовірність прийняття зразка, у якого $z$ точно дорівнює $z_{2}$ (але не ймовірність прийняти зразок, що не задовольняє вимоги взагалі); $\varepsilon-$ умовна ймовірність забракувати зразок, у якого $z$ точно дорівнює $z_{1}$ (але не ймовірність забракувати будь-який придатний зразок).

Разом 3 тим для різних зразків $z$, будучи величиною випадковою, непостійна, а ймовірність реалізації подій $\left\{z=z_{1}\right\}$ або $\left\{z=z_{2}\right\}$ мізерно мала (для суцільних розподілів, подібних до зображеного на рис. 2, ця ймовірність, як зазначалося, дорівнює нулю). Таким чином, фактична ймовірність прийняти зразок, який не відповідає вимогам (коли $z>z_{2}$ ), не дорівнює значенню ризику, що 
приймається при плануванні, яке передбачає підтвердження малоймовірної події. Це справедливо як відносно ризику замовника, так і ризику постачальника.

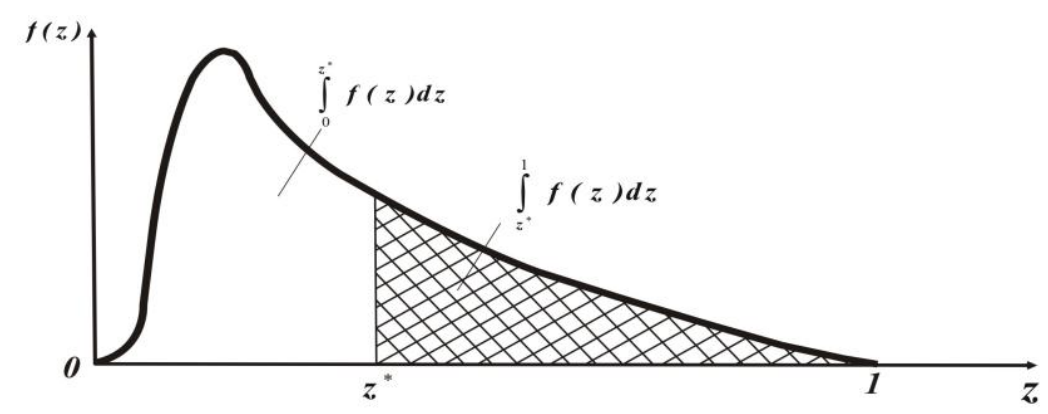

Рис. 2. Функція розподілу ймовірності відмови

У випадку, якщо $z^{*}$, як і раніше, $\epsilon$ заданий рівень безвідмовності, справедливі співвідношення

$$
\left.\begin{array}{l}
\operatorname{Bep}\left\{z \leq z^{*}\right\}=\int_{0}^{z^{*}} f(z) d z \\
\operatorname{Bep}\left\{z \succ z^{*}\right\}=\int_{z^{*}}^{1} f(z) d z
\end{array}\right\},
$$

на підставі яких можна планувати відповідний обсяг випробувань не за малоінформативними

умовними ймовірностями $\varepsilon$ i $\phi$, а за реальним ризиком, усередненим на множині значень $z(T)$. Це ризик, який визначається як ефективний, являє собою такі ймовірності: ризик замовника $\phi_{e \phi}-$ ймовірність прийняти зразок, який не відповідає вимогам щодо безвідмовності, тобто при
$z(T)>z^{*}(T)$; ризик постачальника $\varepsilon_{e \phi}-$ ймовірність бракування зразка, який відповідає таким вимогам, тобто при $z(T) \leq z^{*}(T)$. Отже,

$$
\begin{aligned}
\phi_{e \phi} & =\int_{z^{*}}^{1} P[z(T)] f[z(T)] d z, \\
\varepsilon_{e \phi} & =\int_{0}^{z^{*}}\{1-P[z(T)]\}[z(T)] d z .
\end{aligned}
$$

При плануванні випробувань методом однократної вибірки (випробовують партію $3 \mathrm{~N}$ зразків протягом часу $\tau$, i партію приймають, якщо число відмов $\mathrm{n}$ не перевищує деякої заданої величини $n^{*}$ ) ймовірність приймання партії визначається з виразу

$$
P[z]=P\left\{n=n^{*}\right\}=\sum_{i=0}^{n^{*}}(\underset{i}{N}) z^{i}(1-z)^{N-i}
$$

3 огляду на те, що $z(T)$ обмежена значеннями 0 i 1 , iï імовірнісну щільність можна описати бета - розподілом:

$$
f[z]=\frac{\Gamma(k+\chi)}{\Gamma(k) \Gamma(\chi)} z^{k-1}(1-z)^{\chi-1}
$$


де $\tilde{A}(k), \tilde{A}(\chi), \tilde{A}(k+\chi)$ - гаммафункції відповідних аргументів.

Отже, підставивши (6) i (7) в (4) i (5), можна після інтегрування отримати вирази для ефективного ризику в загальному вигляді.

Для спрощення викладок і щоб не порушити спільності, покладемо $k=2$. В такому випадку

$$
\begin{aligned}
& \phi_{e \phi}=\frac{\Gamma(\chi+2)}{\Gamma(\chi)} \int_{z^{*}}^{1} z(1-z)^{\chi-1} \sum_{i=0}^{n^{*}}(\underset{i}{N}) z^{i}(1-z)^{N-i} d z \\
& \varepsilon_{e \phi}=\frac{\Gamma(k+2)}{\Gamma(\chi)} \int_{0}^{z^{*}} z(1-z)^{\chi-1}\left[1-\sum_{i=0}^{n^{*}}\left(N_{i}\right) z^{i}(1-z)^{N-i}\right] d z
\end{aligned}
$$

Інтегрування виразів (8) і (9) зробимо для важливого в практиці випадку, коли має бути реалізована умова про відсутність відмов у процесі випробувань, тобто при $n^{*}=0$. Тоді з (8) і (9) отримаємо

$$
\begin{gathered}
\phi_{e \phi}=\frac{\chi(\chi+1)\left(1-z^{*}\right)^{N+\chi}}{N+\chi}\left(z^{*}+\frac{1-z^{*}}{N+\chi+1}\right) \\
\varepsilon_{e \phi}=1-\chi(\chi+1)\left[\frac{1}{(N+\chi)(N+\chi+1)}+\left(z^{*}+\frac{1-z^{*}}{\chi+1}\right) \times \frac{\left(1-z^{*}\right)^{\chi}}{\chi}-\right. \\
\left.-\left(z^{*}+\frac{1-z^{*}}{N+\chi+1}\right) \frac{1-z^{*}}{N+\chi}\right]
\end{gathered}
$$

Графічні залежності за виразами (10) та (11) наведені на рис. 3 , 3 якого видно, що при $\mathrm{z}=0,02$ із зростанням ризик замовника знижується, але не різко.

Продиференціювавши (10), можна бачити, що при заданих $N$ i $z^{*}$ ефективний ризик замовника має явно виражений максимум $\frac{\delta^{2} \phi_{a \hat{o}}}{\eta \chi^{2}}<0-$ при певному значенні $\chi$, тобто існує деякий найбільш несприятливий 3 точки зору замовника розподіл $Z$, при якому ризик $\phi$ максимальний. Аналогічна картина i y відношенні ризику $\varepsilon$. Останнє служить виправданням того, що для традиційних планів ризик вибирають виходячи 3 точних значень $z_{1}$ і $z_{2}$ (такі плани розраховані на гірший випадок - модальний). Планувати випробування виходячи з гіршого випадку виправдано в умовах, коли про випробовуваному зразку немає інформації, a це для вузлів силового обладнання нехарактерно.

Дані рис. 3 дозволяють встановити, що ризики, відповідні математичним очікуванням випадкової величини $\mathrm{z}$, істотно зміщені униз по відношенню до їх модальних значень: наприклад, при $\mathrm{N}=6$, 


$$
\beta(z=0.02)_{\max }=0,83, \quad \text { в } \quad \text { той } \quad \text { час } \quad \text { як } \quad \beta(z=0.02)_{\{z / \gamma=100)}=0,39 .
$$

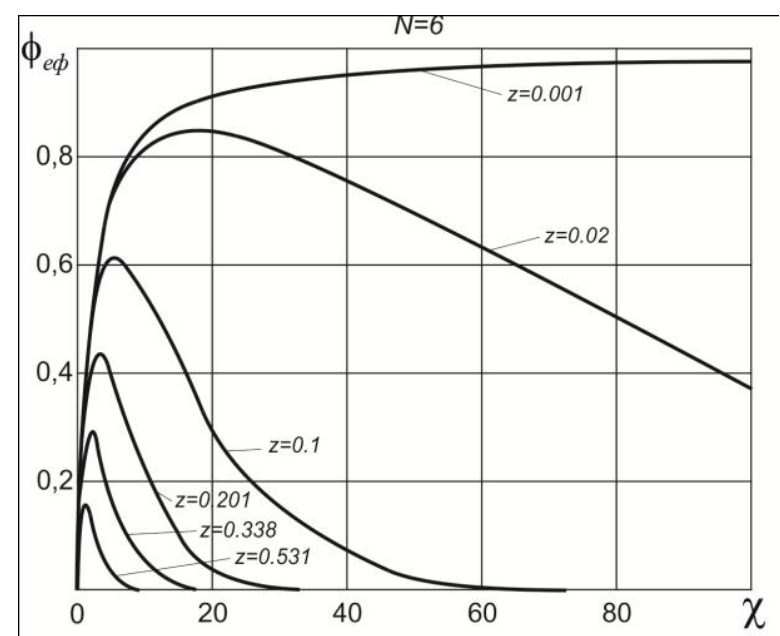

a)

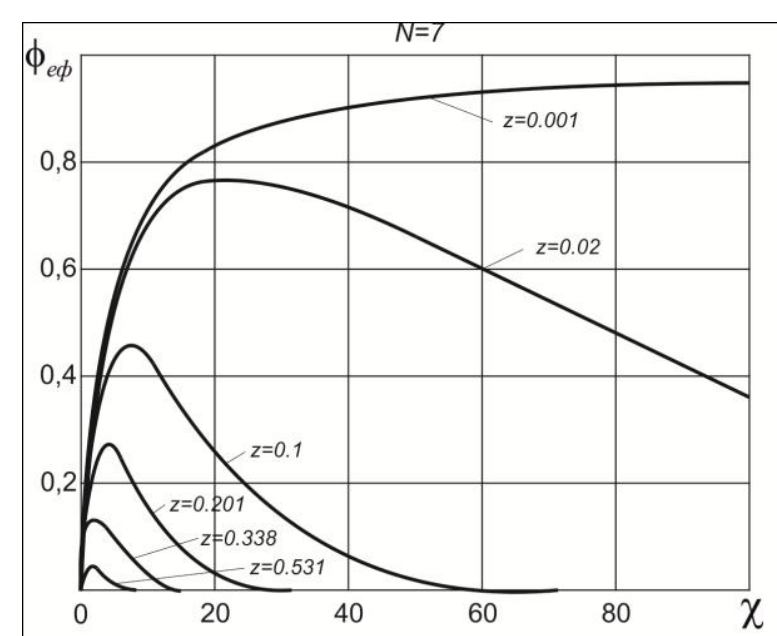

б)

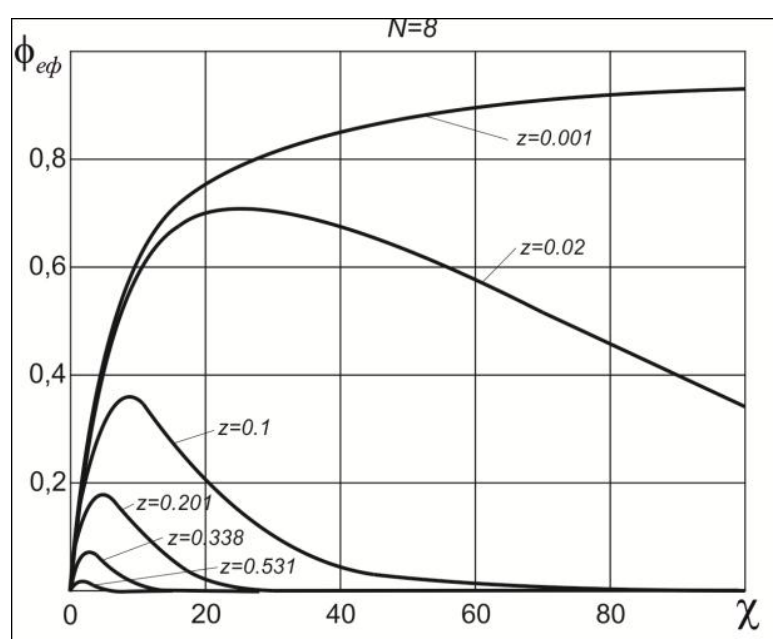

B)

Рис. 3. Залежність ефективного ризику замовника від ймовірності відмови випробувальних вузлів

\section{Висновки:}

1. Запропоновано методику, яка дозволяе планувати обсяг проведення випробувань вузлів силового обладнання ТРС 3 урахуванням накопиченої експлуатаційної інформації щодо відмов.

$$
\text { 2. Побудовані }
$$
залежності ефективного ризику, які при проведенні випробувань дозволяють організувати самонавчання процесу проведення випробувань 3 аргументацією вихідного імовірнісного розподілу величини, що характеризує безвідмовність у подальшому вузла, який випробовується.

3. Отримані дані дозволяють встановити, що ризики, які відповідають математичним очікуванням випадкових величин $z$, істотно зміщені униз по відношенню до їх модальних значень. 


\section{Список літератури}

1. Биргер, И.А. Техническая диагностика [Текст] / И.А. Биргер. - М.: Машиностроение, 1978. - $240 \mathrm{c}$. $564 \mathrm{c}$.

2. Вентцель, Е.С. Теория вероятностей [Текст] / Е.С. Вентцель. - М.: Физматгиз, 1962. -

3. ГОСТ 18242-72. Статистический приемочный контроль по альтернативному признаку. Планы контроля [Текст]. - М.: Издательство стандартов, 1972.

4. Статистические методы обработки статистических данных [Текст]. - М.: Издательство стандартов, 1978. - 230 с.

5. Четвергов, В.А. Надежность локомотивов [Текст] / В.А. Четвергов, А.Д. Пузанков. М.: Маршрут, 2003. - 415 с.

Ключові слова: організація, випробування, силове обладнання, ризик, зразок, функція.

\section{Анотаціï}

У статті запропоновано проведення випробувань силового обладнання тягового рухомого складу з урахуванням ефективного ризику. Отримано залежності ефективного ризику замовника від ймовірності відмови випробувальних вузлів.

В статье предложено проведение испытаний силового оборудования тягового подвижного состава с учетом эффективного риска. Получены зависимости эффективного риска заказчика от вероятности отказа испытуемых узлов.

The article suggested that the tests of power equipment traction vehicles including effective risk. The dependences of the effective risk of failure probability of the customer test sites. 